\title{
Revised standards for triceps and subscapular skinfolds in British children
}

\author{
J. M. TANNER and R. H. WHITEHOUSE \\ From the Department of Growth and Development, Institute of Child Health, University of Lcn ton
}

\begin{abstract}
Tanner, J. M., and Whitehouse, R. H. (1975). Archives of Disease in Childhood, 50, 142. Revised standards for triceps and subscapular skinfolds in British children. Revised centile standards are given for triceps and subscapular skinfold measurements in boys and girls aged from one month to 19 years. The school age data are based on London mesurements made in 1966, and the infant data on Midland Infant Welfare Clinic figures in 1966-67. All centiles are above those given in the earlier standards published in 1962, and particularly so in infancy. It is emphasized that the standards represent what is, not what ought to be.
\end{abstract}

The standards at present used for subcutaneous fat measured by skinfold calipers in children (Tanner and Whitehouse, 1962) are based on measurements made some 15 years ago. We now therefore present a new set of centiles based on more recent data.

\section{Technique and sites of measurement}

The skinfolds are measured by picking up a fold of skin and subcutaneous tissue between the thumb and forefinger, initially placed about $2 \mathrm{~cm}$ apart on the skin, and pinching it away from the underlying muscle in the manner shown in Fig. 1 and 2. The width of the skinfold is measured with a caliper designed to give a constant pressure of $10 \mathrm{~g} / \mathrm{mm}^{2}$ over its entire opening range (Tanner and Whitehouse, 1955). The instrument is held as illustrated, the jaws are applied to the skinfold just under the pinch point and the right hand is allowed to relax entirely its grip on the handle so that the jaws can exert their full pressure. The left hand maintains the pinch throughout the measurement. This usually results in a stable reading up to $20 \mathrm{~mm}$, but above this the measurement registered sometimes decreases as the measurer watches the dial. A firmer grip by the left hand may prevent this: if not, then the reading should be taken two seconds after the caliper is applied. The dial of the caliper illustrated (Holtain Skinfold Caliper) is calibrated to $0.2 \mathrm{~mm}$, but the measurement can be conveniently estimated to the last completed $0.1 \mathrm{~mm}$.

Skinfolds can only be measured accurately at sites where a proper fold can be raised clear of the tissues underneath. The two sites considered here are the most satisfactory ones and can be cleanly picked up in all but the most obese children (in whom no valid

Received 24 July 1974. skinfold measurements are possible). One site is on a limb, the other on the trunk; since considetable differences occur between body and limb fat in growth curves, and in reaction to certain hormones (see Tanner and Whitehouse, 1967), both should be measured.

The triceps skinfold is measured half-way down the left arm, which should hang relaxed at the subject's side. The tips of the acromial process and the olecranon are palpated, and a point halfway between marked

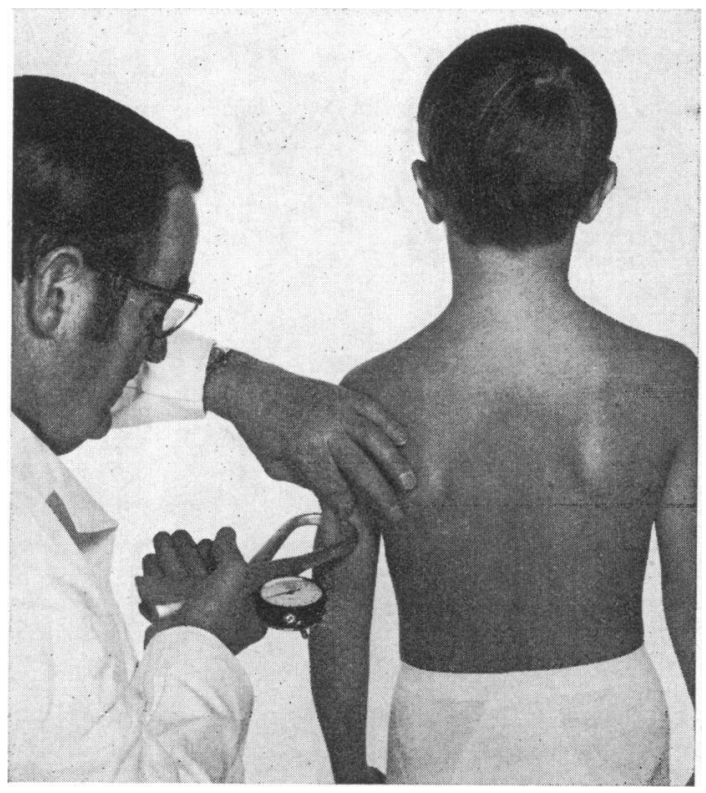

FIG. 1.-Measurement of triceps skinfold. 


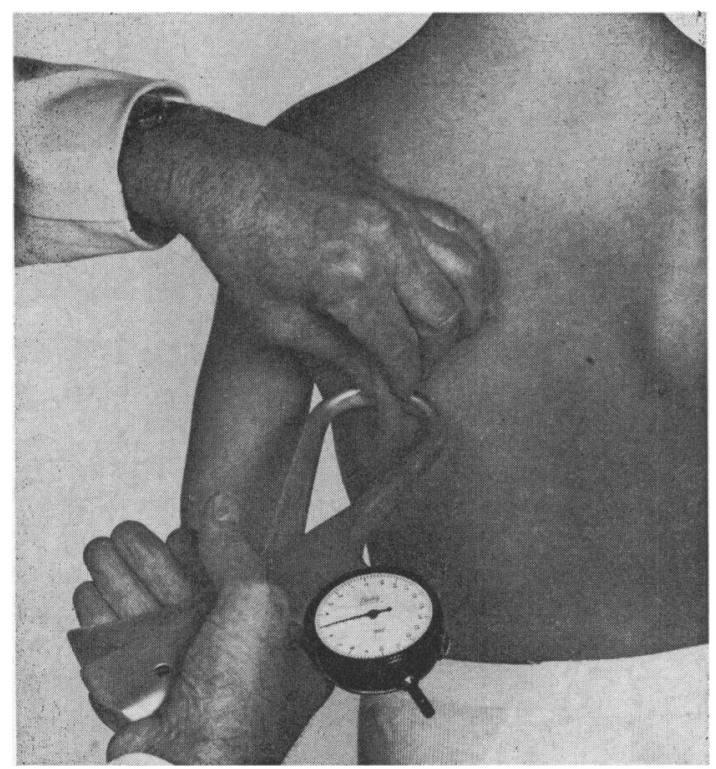

Fig. 2.-Measurement of subscapular skinfold.

on the skin. The skinfold is picked up over the posterior surface of the triceps muscle on a vertical line passing upwards from the olecranon in the axis of the limb, and the caliper jaws are applied at the marked level. Care should be taken to locate the site right on the back of the arm, truly above the olecranon, for different values are obtained halfway round the arm.

The subscapular skinfold is picked up just below the angle of the left scapula with the fold either in a vertical line or slightly inclined, in the natural cleavage line of the skin.

The accuracy of measurements is such that a trained individual should duplicate his readings to within $\pm 5 \%$ in two-thirds or more of all repeated measurements (Edwards et al., 1955). Differences between different observers may be considerably greater than this, however, unless great care is taken in training the observers together and in keeping them so trained. This is due to individual differences in the manner of locating and picking up the skinfold (see Ruiz, Colley, and Hamilton, 1971).

Because the values obtained with the skinfold caliper give a markedly non-gaussian frequency distribution it is necessary for most purposes to transform them to a log scale before use. The most appropriate transformation, which serves reasonably well for all sites and ages, and both sexes, is: 18).

Skinfold transform $=100 \log _{10}$ (reading in $0.1 \mathrm{~mm}-$

A table of the transformation is given in Edwards et al. (1955). Both scales are given in the standards, however, so that plotting of the untransformed measurement is all that is required.
The sources of the standards are:

(a) One month to 1 year, 200 children followed longitudinally in Bakewell, Derbyshire Infant Welfare Clinics, by kind permission of the late Dr. B. Hutchinson-Smith (1973) and Dr. R. A. Dixon (personal communication, 1974).

(b) 1 to 5 years; London Institute of Child Health group of the International Children's Centre Longitudinal Growth Study: 50-100 children of each sex each year; three measurers. Random sample of children born in the West Central Area of London.

(c) 5 to 19 years; ILEA survey of London schoolchildren 1966 (unpublished). Approximately 1000 children of each sex at each year of age; nine measurers all trained by the authors over 2-day period. A random sample of London schools was taken and all children measured. At ages above 16, technical schools were selected.

\section{Construction and use of the standards}

The standards (Fig. 3, 4, 5, 6) were constructed in the same way as the earlier ones (Tanner and Whitehouse, 1962). They are cross-sectional in type so that an individual's curve of growth may show steeper rises and falls, especially in infancy and at puberty (see discussion in Tanner, Whitehouse, and Takaishi, 1966). The centile lines have been smoothed graphically.

\section{Discussion}

These standards are only applicable to measurements taken with the Harpenden or Holtain caliper, using correct technique. By international agreement all skinfold calipers are supposed to exert a constant pressure of $10 \mathrm{~g} / \mathrm{mm}^{2}$ at all openings (Weiner and Lourie, 1969). Calipers such as the Best or Lange, which exert greater pressures and have different shapes of contact surface produce different readings, the difference varying with sex and site (Clegg and Kent, 1967; Parizkova and Goldstein, 1970).

The left side of the body is used, following an international convention established by anthropologists some 80 years ago, and re-emphasized in the protocol of the International Biological Programme (Weiner and Lourie, 1969). Unfortunately a more recent convention of using the right side has grown up among certain nutritionists; it is uncertain how much difference this may make in the use of the standards.

Changes from 1962 standards. In general all the centiles are higher than those of the previous standards. This is particularly so in the first 2 years. The new triceps 50 th centiles at 1 year old approximate the old 95th (boys) and 75th (girls). The new subscapular centiles show an earlier peak in infancy than the old ones, at 6 months rather than 1 year. At 6 months the new 50th centiles 


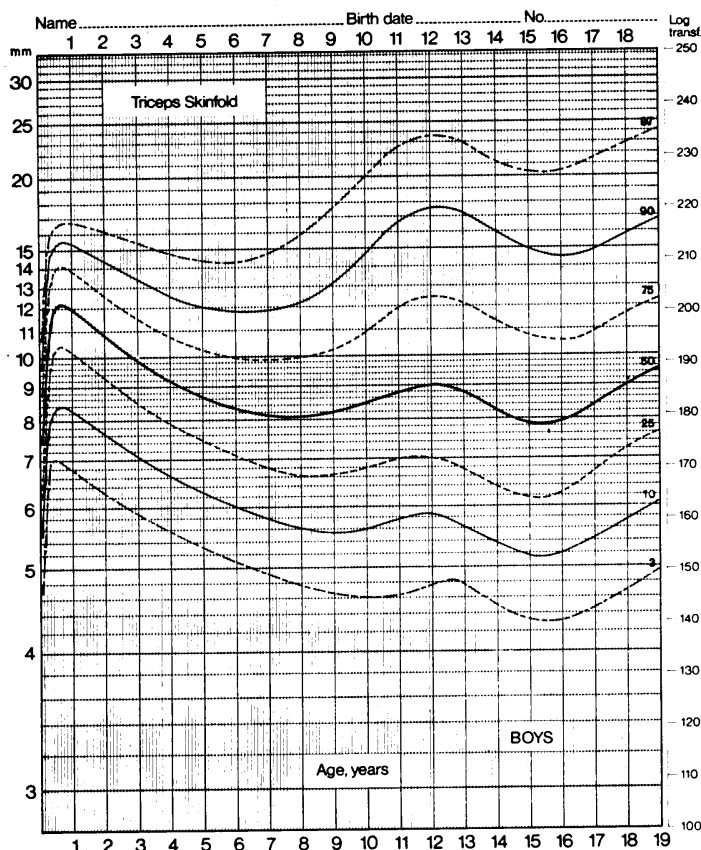

FIG. 3.-Triceps skinfold standard, boys.

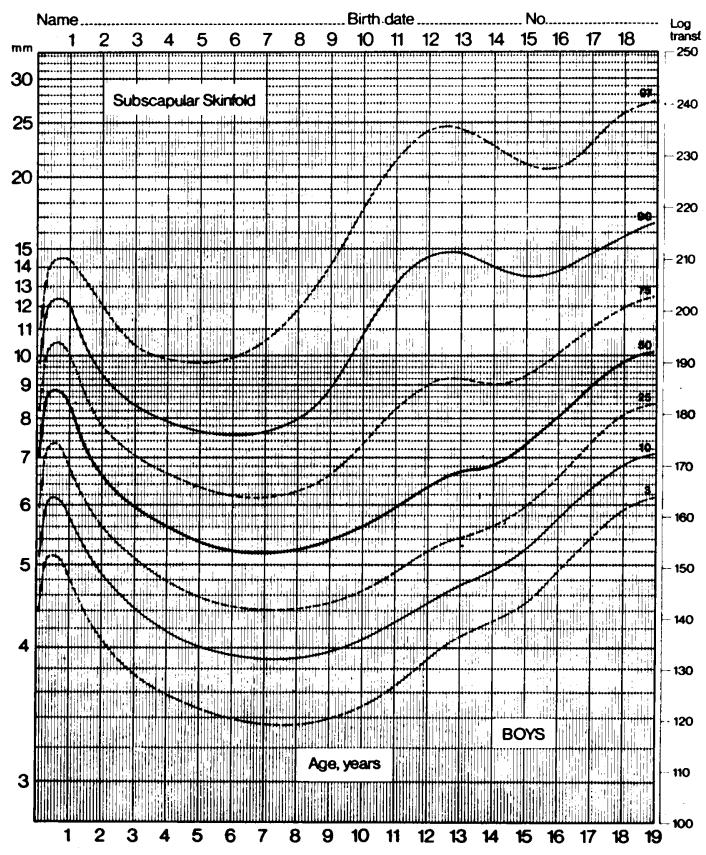

FIG. 5.-Subscapular skinfold standard, boys.

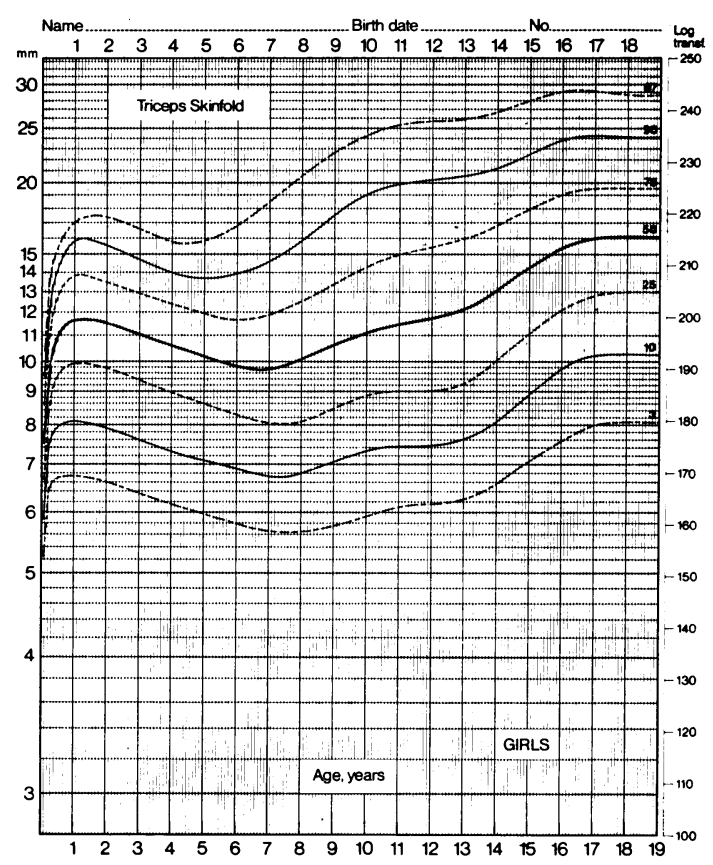

FIG. 4.-Triceps skinfold standard, girls.

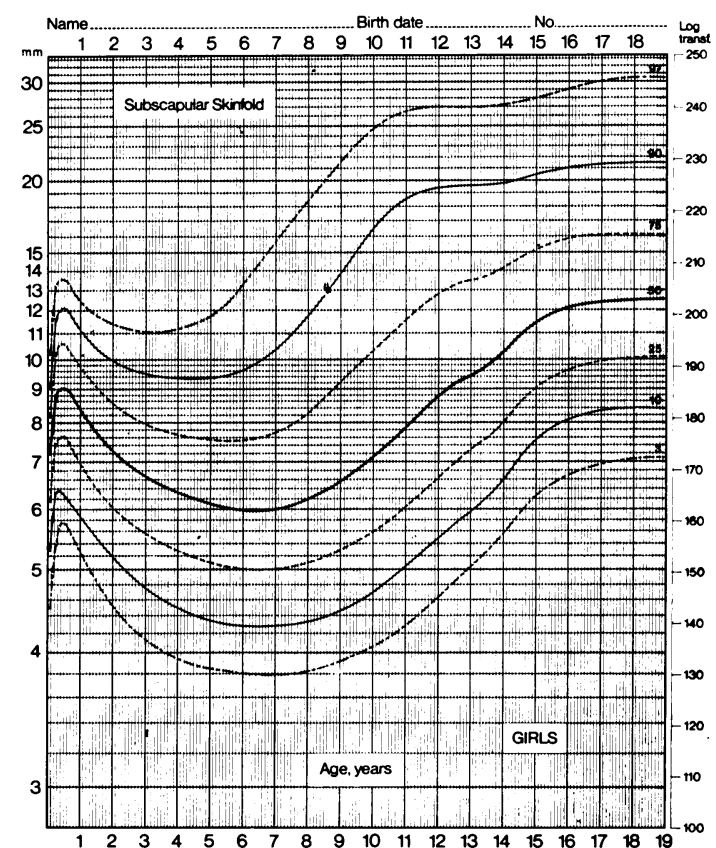

FIG. 6.-Subscapular skinfold standard, girls. 
approximate the old 95th, for both sexes. At school age, however, the shift is much less, the new 50th being at about the position of the old 55th-60th.

Actual not optimal. Finally it must be emphasized that these standards aim to represent the actual centiles observed and imply nothing as to the desirability or undesirability of a population having this distribution of subcutaneous fat. Certainly children at either extreme should be regarded as at risk, the 3rd centile child being perhaps undernourished, and the 97th being certainly obese. Probably an optimally-nourished population would have 3 rd and 10th centiles a little above these, 50th centiles a little below, and 90th and 97th much below. The marked peak in infancy may reflect excessive use of bottle and baby food; in Swedish breast-fed babies the 50th centile peaks are about $2 \mathrm{~mm}$ lower (P. Karlberg, personal communication, 1974).

We are most grateful to the late Dr. B. HutchinsonSmith for permission to use her infant data, and to Dr. R. A. Dixon for generously giving us his computations of the infant centiles.

The caliper is obtainable from Holtain Ltd., Crosswell, Crymmych, Pembs., U.K., and the charts from Creaseys of Hertford Ltd., Bull Plain, Herts., U.K.

Fig. 1 reproduced by permission of the Editors of the Archives.
REFERENCBS

Clegg, E. J., and Kent, C. (1967). Skinfold compressibility in young adults. Human Biology, 39, 418.

Edwards, D. A. W., Hammond, W. H., Healy, M. J. R., Tanner, J. . M., and Whitehouse, R. H. (1955). Design and accuracy of calipers for measuring subcutaneous tissue thickness. British fournal of Nutrition, $9,133$.

Hutchinson-Smith, B. (1973). Skinfold thickness in infancy in relation to birthweight. Developmental Medicine and Child Neurology, 15, 628.

Parizkova, J., and Goldstein, H. (1970). A comparison of skinfold measurements using the Best and Harpenden calipers. Human Biology, 42, 436.

Ruiz, L., Colley, J. R. T., and Hamilton, P. J. S. (1971). Measurement of triceps skinfold thickness: an investigation of sources of variation. British fournal of Preventive and Social Medicine, $25,165$.

Tanner, J. M., and Whitehouse, R. H. (1955). The Harpenden skinfold caliper. American fournal of Physical Anthropology, $13,743$.

Tanner, J. M., and Whitehouse, R. H. (1962). Standards for subcutaneous fat in British children. Percentiles for thickness of skinfolds over triceps and below scapula. British Medical fournal, 1, 446.

Tanner, J. M., and Whitehouse, R. H. (1967). The effect of human growth hormone on subcutaneous fat thickness in hyposomatotrophic and panhypopituitary dwarfs. Fournal of Endocrinology, 39, 263.

Tanner, J. M., Whitehouse, R. H., and Takaishi, M. (1966). Standards from birth to maturity for height, weight, height velocity, and weight velocity; British children 1965. Archives of Disease in Childhood, 41, 454, 613.

Weiner, J. S., and Lourie, J. A. (1969). Human Biology: A Guide to Field Methods, p. 12. International Biological Programme Handbook No. 9. Blackwell Scientific Publications, Oxford.

Correspondence to Professor J. M. Tanner, Department of Growth and Development, Institute of Child Health, 30 Guilford Street, London WC1N 1EH. 